\title{
Stereological investigation of the effects of curcumin on the damage in the hippocampus of developing rat brain caused by valproic acid
}

\author{
Burcu Demirela*, Banu Eren $^{\mathrm{b}}$, Dilek Sağırc \\ ${ }^{a}$ Department of Forestry, Akkuş Vocational High School, Ordu University, Akkuş, Ordu, Turkey \\ ${ }^{b}$ Department of Biology, Faculty of Arts and Science, Ondokuz Mayls University, Samsun, Turkey \\ ${ }^{c}$ Health High School, Sinop University, Sinop, Turkey
}

\author{
ARTICLE INFO \\ * Correspondence to: \\ Burcu Demirel \\ Department of Forestry, \\ Akkuş Vocational High School, \\ Ordu University, Ordu, Turkey \\ e-mail: bioburcudemirel@gmail.com
}

\section{Keywords:}

Curcumin

Hippocampus

Stereology

Valproic Acid

\section{ABSTRACT}

Valproic acid is an antiepileptic drug used for the treatment of seizures in newborns, children and adults. Despite having positive effect in the treatment of epilepsy, valproic acid may adversely affect brain function and brain development. Antioxidant and neuroprotective properties of curcumin are well-known. Curcumin has a significant effect in the treatment of various diseases caused by oxidative stress. In the light of this information, the study aimed to determine the adverse effects of valproic acid in the number of pyramidal cells in the hippocampus of the developing rat brain and whether curcumin has protective effects against these adverse effects. A total of 50 Wistar male rats were divided into two groups as 7 and 14 day old. Each group was subdivided into five groups as control, curcumin, dimethyl sulfoxide, valproic acid, valproic acid+curcumin. After dissolving in $10 \%$ dimethylsulfoxide, the rats in each group received intraperitoneal injection of valproic acid $(400 \mathrm{mg} / \mathrm{kg})$ and curcumin $(200 \mathrm{mg} / \mathrm{kg})$. Rats were sacrificed 24 hours after the last injection. After histological processes, stereological analysis was performed using optical fractionation technique. Overall number of neurons in the left hippocampus (CA1, CA2, CA3 and CA4) of the 7 and 14 day old rats was estimated and average numerical values were determined. The mean total neuron numbers and standard deviations for 7 day old rats were $727224 \pm 4531.7$ in control group; $312232.8 \pm 15853.3$ in valproic acid group and $431665.4 \pm 28464.5$ in valproic acid+curcumin group. These numerical values were $508160.6 \pm 21985.2 ; 313958.9 \pm 18199.66$ and $456028.8 \pm 24942.9$ for 14 day old rats respectively. The results support the idea that curcumin can be a potential protective and effective agent in the prevention of histological neuronal damage that may occur in the developing rat brain due to valproic acid treatment. We are in the opinion that the results of this study will shed light on clinical studies and form a basis to antioxidant studies involving the use of valproric acid.

J. Exp.Clin. Med., 2014; 31:122 